\title{
OBSTRUÇÃO PARCIAL DE ÁRVORE BRÔNQUICA POR RAMO DE Araucaria angustifolia EM EQUINOS
}

(Partial obstruction of bronchial tree by branch of Araucaria angustifolia in equines)

\begin{abstract}
Andressa Duarte Lorga, Anny Raissa Carolini Gomes, Jéssica do Rocio Janiszewski, Lucimara Strugava, Ivan Deconto, Peterson Triches Dornbusch
\end{abstract}

Universidade Federal do Paraná, Curitiba, PR, Brasil.

*Correspondência: lalorga2@hotmail.com

Resumo: O diagnóstico de corpos estranhos em árvore traqueobrônquica é comum na pediatria, sendo considerado emergencial nesses indivíduos, entretanto em grandes animais os casos são pouco relatados. A Araucaria angustifolia, árvore comum da região sul do Brasil, caracteriza-se por suas folhas pontiagudas, regionalmente conhecidas como "grimpas"; ocasionalmente os equinos ao pastejar podem aspirá-las e, devido à particularidade da folha, causam lesões traqueobrônquicas graves nesses animais. No período de março de 2019 a fevereiro de 2020, foram atendidos no Hospital Veterinário da Universidade Federal do Paraná (HV-UFPR), três equinos, Crioulos, entre dois a dez anos de idade, com histórico de tosse crônica, eventual dificuldade respiratória e intolerância ao exercício, secreção nasal unilateral purulenta e hálito fétido. Um dos pacientes, uma potra de dois anos, apresentou na propriedade, febre de $39,8^{\circ} \mathrm{C}$ e grave dificuldade respiratória, necessitando de atendimento emergencial, onde foi realizado sondagem nasotraqueal para alívio respiratório, porém o procedimento não foi efetivo, sendo necessário o encaminhamento do animal ao Hospital Veterinário. Os pacientes encaminhados, além dos sinais já citados no histórico clínico, também apresentavam ausculta pulmonar alterada, mostrando discreta crepitação. Devido aos sinais clínicos, foi realizado exame endoscópico das vias aéreas desses pacientes. Os animais foram submetidos a broncoscopia, evidenciando em todos os casos, muco espesso no lúmen traqueal e espessamento da carina; durante o exame foi localizado em brônquio principal direito o ramo de Araucaria angustifolia, confirmando o diagnóstico de corpo estranho em árvore traqueobrônquica. O tratamento indicado para esses pacientes é a retirada do corpo estranho via endoscopia, sendo assim, os animais foram sedados (cloridrato de detomidina $1 \%, 0,04 \mathrm{mg} / \mathrm{kg} / \mathrm{IV}$ ) e ao redor do ramo de $A$. angustifolia foi instilado por sonda 20 $\mathrm{ml}$ de anestésico local (cloridrato de lidocaína). Realizado a anestesia local iniciou-se a retirada do material, inicialmente utilizando uma pinça de Corpo Estranho Jacaré para desfolhar o ramo e após desfolhado, empregando uma Alça de Polipectomia realizou-se a retirada do corpo estranho. Em um dos pacientes, o ramo estava verde e firmemente aderido, sendo necessário quatro procedimentos para retirada do material, pois devido a manipulação, as folhas pontiagudas lesionavam a mucosa, ocasionando sangramentos que impediam a visualização do corpo estranho; portanto os procedimentos foram realizados com intervalos de cinco dias, e durante os intervalos foi instituído corticoterapia (dexametasona $0,2 \mathrm{mg} / \mathrm{kg} / \mathrm{IV}$ ) para amenizar a irritação causada pela manipulação do corpo estranho. Após o procedimento todos os equinos receberam antibioticoterapia (penicilina benzatina $3000000 \mathrm{UI}, 20000 \mathrm{UI} / \mathrm{kg} / \mathrm{IM}$ e ceftioufur 4,4 mg/kg/IM), terapia analgésica (flunixim meglumine $50 \mathrm{mg}, 1,1 \mathrm{mg} / \mathrm{kg} / \mathrm{IV}$ ) além de broncodilatador e mucolítico (Cloridrato de Clembuterol e N-Acetílcisteina). Depois de retirado o corpo estranho e realizado a terapia medicamentosa, os pacientes apresentaram melhora total do quadro clínico. O brônquio principal direito dos equinos é mais inclinado em relação ao esquerdo, particularidade anatômica que favorece a parada de corpos estranhos. As araucárias são comuns na região sul do Brasil, sendo assim casos de obstruções parciais traqueobrônquicas por ramos de $A$. angustifolia podem ocorrer, ocasionando danos graves quando não retirados, portanto a broncoscopia é importante para o diagnóstico e tratamento desses casos.

Palavras-chave: araucária; corpo estranho; endoscopia; pulmão 


\section{Referências}

ARAÚJO, F.F., CASTRO, M.L., DECONTO, I., DORNBUSCH, P.T., DE BARROS FILHO, I.R., FINGER, M.A. Corpo estranho em arvore traqueobronquica em equina-relato de caso. Revista de Educação Continuada em Medicina Veterinária e Zootecnia do CRMV-SP. v.12, n.1, p.76, 2014.

BARUSSI, F.C.M., BASTOS, F.Z., ZENNI, L., CAMARGO, C.E., MICHELOTTO, P.V. Pine branch of Araucaria angustifolia in horse bronchi: A series of four cases. Equine Veterinary Education. v.32, p. 393-397, 2019. 